\title{
MENEROPONG OTENTISITAS HADITS MELALUI ILMU NAQD AL- HADITS
}

\author{
Ainul Yaqin \\ Universitas Islam Majapahit, Mojokerto
}

\begin{abstract}
ABSTRAK
Diskursus tentang otentisitas hadits merupakan salah satu hal yang sangat krusial dan kontroversial.Problem seperti ini bukan tidak disadari oleh umat Islam, bahkan sejak abad pertama hijriyah, umat Islam sudah melakukan upaya-upaya untuk menciptakan metode dalam mendapatkan hadits yang otentik.Salah satu metode yang dikembangkan oleh umat Islam untuk mengetahui apakah hadits yang kita terima itu otentik atau tidak adalah dengan melakukan kritik hadits (naqd al-hadits). Naqd alhaditsdibagi menjadi tiga, naqd al-khariji, naqd al-dakhili dan naqd al-dakhili wa al-khariji. Kritik hadits berguna untuk menjaga agar jangan sampai masuk segala sesuatu yang bukan hadits menjadi bagian dari hadits, karena hal itu akan menyebabkan penyimpangan ajaran Islam.

Kata kunci: Otentisitas, Naqd al-hadits, Pendekatan historis.
\end{abstract}

\section{A. Pendahuluan}

Keberadaan Hadits sebagai sumber hukum Islam kedua setelah Al-Qur'an, tidak lagi menjadi perdebatan di kalangan mayoritas muslim. Berbagai dalil baik dari Al-Qur'an maupun Hadits telah memberikan peneguhan bahwa umat Islam harus berpegang teguh kepada Hadits.

Dalam Al-Quran dinyatakan:

"Dan tidaklah apa yang diucapkan Muhammad berasal dari hawa nafsunya, melainkan berasal dari wahyu ..."1

\footnotetext{
${ }^{1}$ Al-Qur'an al-Karim, Surah An Najm: 3-4.
} 
Firman Allah SWT di atas memberikan penjelasan kepada Umat Islam bahwa apapun yang keluar dari bibir Baginda Nabi Besar Muhammad SAW - yang disebut dengan hadits - adalah bersumber dari Allah (wahyu). Sebab ucapan Muhammad merupakan wahyu, maka berarti ucapan Muhammad adalah benar. Oleh karena itu, dijelaskan pula oleh Allah SWT dalam ayat al-Qur'an Surah al-Hasyr (59: 7) bahwa wajib bagi setiap muslim untuk mengambil (mengetahui, memahami dan mengamalkan) apapun yang bersumber dari Rasulullah.

Tetapi terdapat problem yang sangat serius bagi umat Islam dalam mendapatkan hadits yang otentik (shahih), sebab hadits-hadits itu baru ditulis setelah 1 abad sepeninggal Rasulullah SAW. Oleh karena itu, ada pertanyaan besar apakah hadits-hadits yang berada di tangan kita saat ini betul-betul bersumber dari Rasulullah ataukah merupakan uncapan orang lain yang diatasnamakan kepada Beliau yang disebut dengan hadits palsu. Akan sangat berbahaya apabila hadits-hadits yang kita jadikan rujukan beragama adalah ucapan seseorang yang dinisbatkan kepada Rasulullah, sebab itu berarti telah mencampurkan pemikiran manusia ke dalam ajaran agama dan hal itu adalah penyimpangan terhadap ajaran Islam.

Diskursus tentang otentisitas hadits merupakan salah satu hal yang sangat krusial dan kontroversial, sebab adanya suatu asumsi bahwa hadits Nabi secara normative-teologis tidak ada garansi dari Allah. Berbeda dengan Al-Qur'an yang oleh Allah sendiri diberi "garansi akan keterpeliharaannya" (Q.S. al-Hijr; 9). Disamping itu, adanya pemalsuan hadits untuk kepentingan tertentu juga menyebabkan rumitnya kita mendapatkan otentisitas hadits.

Problem seperti ini bukan tidak disadari oleh umat Islam, bahkan sejak abad pertama hijriyah umat Islam sudah melakukan upaya-upaya untuk menciptakan metode dalam mendapatkan hadits yang otentik. 
Salah satu metode yang dikembangkan oleh umat Islam untuk mengetahui apakah hadits yang kita terima itu otentik atau tidak adalah dengan melakukan kritik hadits (naqd al-hadits).

\section{B. Sejarah Dan Perkembangan Naqd al-Hadits}

Secara etimologi kata naqd adalah lawan kata nasi'ah (khilaf alnasi'ah) yang berarti alat menimbang dirham (tamyiz al-darahim). ${ }^{2}$ Menurut Muhammad Musthafa Azami, ${ }^{3}$ kata naqd mempunyai arti yang sama dengan kata yamiz dalam Al-Qur'an Surah Ali Imran ; 197, yang berarti memisahkan sesuatu dari sesuatu yang lain. ${ }^{4}$ Dengan demikian, secara terminology naqd adalah alat/cara untuk memisahkan sesuatu dari sesuatu yang lain.

Adapun hadits, secara etimologi adalah lawan kata qadim (naqyd al-qadim). ${ }^{5}$ Menurut Abdul Baqa ${ }^{6}$ hadits adalah isim (kata benda) dari tahdits yang berarti pembicaraan. Kemudian didefinisikan

\footnotetext{
${ }^{2}$ Ibnu Mandhur, Lisan al-Arabi, Jilid III, (Dar al-Fikr, Beirut Libanon), 425.

${ }^{3}$ Adalah Ulama Hadits Kontemporer kelahiran India (tahun 1932), satu decade dengan Yusuf Qardlawi, Muhammad Ghazali dan Muhammad Syahrur. Beliau adalah Dosen Fakultas Tarbiyah Universitas Riyadh Saudi Arabia. Beliau juga aktif menulis buku tentang hadits salah satunya adalah Studies in Hadith Methodology and Literature. Lihat Abdul Mustaqim, Teori Sistem Isnad Hadits Menurut Perspektif Muhammad Musthafa Azami, dalam Fazlurrahman dkk, Wacana Studi Hadits Kontemporer, (Tiara Wacana, Yogyakarta, 2002), 55-61.

${ }^{4}$ Muhammad Musthafa Azami, Memahami Ilmu Hadits; Telaah Methodologi dan Literatur Hadits, (diterjemahkan dari Studies in Hadith Methodology and Literature oleh Meth Kieraha), (Lentera, Jakarta, 2003), 86.

${ }^{5}$ Ibnu Mandhur, Lisan al-Arabi, jilid I, 131.

${ }^{6}$ Nama lengkapnya adalah Ayyub bin Musa al-Husaini al-Quraimi al-Kufawi. Beliau seorang qadhi di Quds, wafat tahun 1093. Lihat Subhi al-Shalih - yang mengutip dari kitab Hidayatul Arifin I, 229 dan Idlah al-Maknun I/251, 380-, Membahas IImu-IImu Hadits, (diterjemahkan dari Ulum al-Hadits wa Musthalahuha oleh Tim Pustaka Firdaus), Cet. II, (Pustaka Firdaus, Jakarta, 1995), 15.
} 
sebagai ucapan, perbuatan atau penetapan yang dinisbatkan kepada Nabi s.a.w. ${ }^{7}$

Dari paparan di atas dapat disimpulkan bahwa yang dimaksud dengan ilmu naqd al-hadits adalah ilmu yang membahas tentang cara/metode untuk membedakan sesuatu (ucapan, perbuatan, ketetapan) yang disandarkan kepada Nabi s.a.w. dari yang lainnya. Atau dalam istilah lain disebut sebagai ilmu kritik hadits.

Istilah naqd al-hadits atau kritik hadits menurut hemat kami baru berkembang dan dipergunakan secara luas di dunia Islam pada masa akhir-akhir ini, sejalan dengan perkembangan keilmuan modern. Walaupun demikian, istilah naqd al-hadits sebetulnya sudah pernah dipakai oleh sebagaian ulama hadits mutaqaddimin (sekitar abad ketiga), tetapi tidak mendapatkan sambutan di kalangan mereka. Mereka lebih condong menamakan ilmu mengenai kritik hadits dengan 'IIm Jarh wa at-Ta'dil. ${ }^{8}$

Tetapi naqd/kritik sebagai sebagai upaya membedakan yang benar dari yang salah tentang hadits sebetulnya sudah dimulai sejak masa Nabi saw. Pada fase ini, kritik hadits tidak lebih dari menemui Nabi saw dan mengecek kebenaran dari apa yang kabarnya dikatakan beliau. $^{9}$

Setelah Nabi wafat dan Islam menyebar dimana-mana, maka hadits pun tersebar diberbagai wilayah dunia Islam. Oleh karena itu, kemungkinan salah pun timbul, akibatnya kritik hadits menjadi nyata. Bahkan, seperempat abad sesudah wafatnya Nabi terjadi bencana besar yaitu fitnah pembunuhan Utsman dan perang antara Ali dan

\footnotetext{
${ }^{7}$ Subhi al-Shalih - yang mengutip dari Kulliyat Abil Baqa', 152-, Membahas IImu-IImu Hadits, (diterjemahkan dari Ulum al-Hadits wa Musthalahuha oleh Tim Pustaka Firdaus), Cet. II, (Pustaka Firdaus, Jakarta, 1995), 15.

${ }^{8}$ Muhammad Musthafa Azami, Memahami Ilmu Hadits; Telaah Methodologi dan Literatur Hadits, (diterjemahan dari Studies in Hadith Methodology and Literature oleh Meth Kieraha), (Lentera, Jakarta, 2003), 86.

${ }^{9}$ lbid, 87.
} 
Mu'awiyah. Disinilah kemudian dimulai pemalsuan hadits dalam arena politik, dengan memuji dan melecehkan partai yang berkepentingan. Dari sini kemudian lahirlah madhab kritik yang bersifat regional, diantaranya adalah madzhab Madinah dan Mazhab Irak yang dipelopori oleh para sahabat dan para tabiin. ${ }^{10}$

Setelah periode tabiin atau sekitar abad kedua hijriah, kritik hadits memasuki fase baru, dimana umat Islam dalam rangka mendapatkan hadits yang shoheh banyak melakukan perjalanan untuk melakukan cross-chek terhadap hadits yang diterimanya. Periode ini melahirkan kritikus hadits seperti Sufyan Al-Tsauri dari Kufah (97-161 H), Malik bin Anas dari Madinah (93-179 H), Syu'bah dari Wasith (83$100 \mathrm{H})$ Al-Auza'l dari Beirut $(88-158 \mathrm{H})$ dan lain-lain. Dari merekalah kemudian lahir murid-murid mereka yang kesohor yaitu, Adz-Dzuhali, Al-Bukhari, Abu Hatim Al-Razi, Muslim bin Hajja An-Naisaburi dan lainlain. ${ }^{11}$

\section{Pembagian dan Methodologi Naqd al-Hadits}

Nuruddin $\mathrm{Ittr}^{12}$ secara implisit membagi naqd al-hadits menjadi tiga, naqd al-khariji, naqd al-dakhili dan naqd al-dakhili wa al-khariji. Naqd al-khariji disebut juga naqd al-sanad (kritik sanad hadits), naqd al-dakhili sama dengan pengertian naqd al-matn (kritik matan hadits), sedangkan naqd al-khariji wa al-dakhili mempunyai padanan kata dengan naqd al-sanad wa al-matn (kritik campuran antara kritik sanad

\footnotetext{
${ }^{10} \mathrm{lbid}, 87-89$.

${ }^{11} \mathrm{lbid}, 89-92$.

${ }^{12}$ Nuruddin Ittr adalah ulama hadits kontemporer. Beliau adalah Dosen Fakultas Syariah Universitas Damsyiq Surya. Beliau menjabat sebagai Ketua Jurusan Ulum al-Qur'an wa al-Sunnah. Lihat halaman depan kitab Manhaj al-Naqd Fi Ulum al-Hadits karya beliau, terbit tahun (Dar al-Fikr, Beirut Libanon, 1998).
} 
hadits dan kritik matan hadits). ${ }^{13}$ Berikut ini akan kami paparkan tentang pembagian naqd al-hadits beserta dengan metode-metodenya mengacu kepada kitab Manhaj al-Naqd Fi Ulum al-Hadits karya Nuruddin Ittr. ${ }^{14}$

1. Naqd al-dakhili

Naqd al-dakhili atau naqd al-matn yaitu menilai hadits dari sisi internalnya dengan mempertimbangkan terhindarnya matan dari syadz dan illat.

Dalam melakukan kritik hadits dari sisi internal, dapat digunakan beberapa metode/ilmu, antara lain :

a. Dengan mengetahui sisi pengucapannya. Metode ini menilai kesahihan hadits dengan melihat apakah hadits itu tergolong kepada hadist qudsy, hadistmarfu', hadits mauquf, dan hadist maqthu'. Ketika sudah diketahui posisi hadits itu, maka dapatlah diketahui kesahihannya.

b. Dengan mengetahui segi-segi cara periwayatannya. Kritik dengan metode ini mempertimbangkan beberapa aspek, diantaranya adalah sebab-sebab keluarnya hadits, nasihkmansukh hadits, perbedaan nash hadist dan muhkam al-hadits

2. Naqd Khariji

Naqd al-khariji atau naqd al-sanad yaitu menilai hadits dari sisi eksternalnya dengan melihat ketersambungan sanad, kekuatan hapalan dan adalah rawi.

Dalam melakukan kritik hadits dari sisi eksternal, dapat digunakan beberapa metode/ilmu, antara lain :

\footnotetext{
${ }^{13}$ Nuruddin Attr, Manhaj al-Naqd Fi Ulum al-Hadits,(Dar al-Fikr, Beirut Libanon, 1998) 11. dan 467-468. Lihat juga Muhammad Muhammad Abu Syahbah, Fi Rihab al-Sunnah AlKtub al-Shahah al-Sittah, 37-39.

${ }^{14} \mathrm{lbid}, 321-485$.
} 
a. Dengan mengetahui ketersambungan sanad. Metode kritik ini menilai kesahihan hadits dengan melihat apakah hadist tersebut pada posisi muttashil, musalsal atau lainnya.

b. Dengan mengetahui keterputusan sanad. Ukuran-ukuran menilai hadits adalah dengan melihat posisi hadits berada di wilayah munqathi', mu'allaq, mughdlal, mudallas atau lainnya.

3. Naqd al-Dakhili wa al-Khariji

Naqd al-Dakhili wa al-Khariji yaitu menilai hadits dari sisi eksternal dan internalnya secara komprehensif, mencakup sisi sanad juga matannya.

Dalam melakukan kritik hadits cara ini, dapat digunakan beberapa metode/ilmu, antara lain :

a. Dengan mengetahui apakah hadits tersebut ifrad atau gharib

b. Dengan mengetahui jumlah perawinya, yatu dengan melihat apakah hadits itu mutawatir, masyhur, mustafidl, atau aziz.

c. Dengan mengetahui ihtilaf periwayatan hadits, yaitu dengan mempertimbangkan tsiqahnya matan atau sanad hadits, syadznya matan dan sanad hadist serta lainnya.

Berbeda dengan Nuruddin Ittr, Muhammad Musthafa Azami menawarkan metode kritik hadits dengan cara komparasi atau perbandingan. Metode ini dapat dipraktekkan dengan beberapa cara, antara lain sebagai berikut ${ }^{15}$ :

1. Memperrbandingan hadits-hadits dari berbagai murid seorang ulama.

2. Memperbandingan pernyataan-pernyataan seorang ulama yang dikeluarkan pada waktu-waktu yang berlainan.

3. Memperbandingan pembacaan lisan dengan dokumen tertulis.

4. Perbandingan hadis dengan teks Al-Qur'an yang berkaitan.

15 Muhammad Musthafa Azami, Memahami IImu Hadits; Telaah Methodologi dan Literatur Hadits, (diterjemahan dari Studies in Hadith Methodology and Literature oleh Meth Kieraha), (Lentera, Jakarta, 2003), 92 -100. 
Metode-metode tersebut di atas apabila dipraktekkan dengan sungguh-sungguh akan dapat memfilter hadits yang benar dan hadits yang palsu.

\section{Urgensi Naqd al-Hadits Dalam Kajian Hadits}

Secara teologis, mayoritas umat Islam menjadikan hadits sebabagi sumber ajaran pokok setelah Al-Qur'an, bahkan hadits dipandang sebagi miftah Al-Qur'an (kunci untuk memahami Al-Qur'an), sebab ia merupakan bayan (ekspalanasi) terhadap ayat-ayat yang umum, global atau yang masih muthlak.

Sebagai konsekuensi dari posisi hadits tersebut, ulama berupaya untuk menjaga otentisitas hadits dengan memberikan pagar yang akan memporak-porandakan hadits yaitu ilmu naqd al-hadits. Kritik hadits berguna untuk menjaga agar jangan sampai masuk segala sesuatu yang bukan hadits menjadi bagian dari hadits, karena hal itu akan menyebabkan penyimpangan ajaran Islam.

Di samping itu muncul pula persoalan lain yang ditaburkan oleh kaum orientalis, yaitu serangan-serangan mereka yang ditujukan kepada keotentikan hadits. Misalnya, Ignaz Goldziher yang berkesimpulan bahwa tak ada satupun hadits Nabi yang benar-benar otentik berasal dari Nabi. J. Schat juga menyatakan, bahwa dulu tidak ada sanad, baru kemudian orang membikin sanad, sehingga seakanakan hadits itu bersambung sampai Nabi. ${ }^{16}$

Karena persoalan hadits juga menyangkut persoalan IslamicStudies dalam konteks kesejarahan, maka pendekatan histories dalam meneliti masalah ini amat sangat kita perlukan. Sebab, jika kajian keislaman hanya didasarkan kepada theological-approach akan cenderung menghasilkan kesimpulan normative-justifikatif dan kurang

\footnotetext{
${ }^{16}$ Abdul Mustaqim, Teori Sistem Isnad Hadits Menurut Perspektif Muhammad Musthafa Azami, dalam Fazlurrahman dkk, Wacana Studi Hadits Kontemporer, (Tiara Wacana, Yogyakarta, 2002), 69.
} 
kritis dalam melihat persoalan, bahkan terkesan tidak ilmiah sama sekali.

Ulama-ulama Hadits telah menunjukkan kepada dunia ilmiah bahwa teori kritik hadits adalah teori yang sesuai dengan cara kerja ilmiah, dimana kritik hadits membekali diri dengan analisis histories dengan metode perbandingan atau cross reference. Oleh karena itu, dengan teori kritik hadits dapatlah dibuktikan bahwa hadits keotientikannya juga dapat dipertanggungjawabkan secara ilmiah pula. $^{17}$

Dari pendekatan kritik hadits inilah kita akan mampu menjawab serangan kaum orientalis dan menjawab tantang keilmuan modern yang menyangkut tentang problem keotentikan hadits.

\section{E. Penutup}

Setelah penulis melakukan kajian terhadap masalah-masalah diatas, maka dapat diambil beberapa kesimpulan yang antara lain sebagai berikut :

1. Kritik hadits (Naqd al-hadits) sudah berlangsung sejak zaman Nabi dengan metode yang masih sederhana yaitu cross-ceck terhadap apa yang dianggap sebagai hadits Nabi kepada Nabi secara langsung.

2. Naqd al-hadits dibagi menjadi tiga, yaitu; Naqd al-Dakhili atau kritik matan, Naqd al-Khoriji atau kritik sanad, dan Naqd al-Dakhili wa alKhariji atau kritik komprehensif matan-sanad. Disamping itu terdapat metode kritik hadits yaitu dengan cara komparasi atau perbandingan.

3. Otentisitas hadits sesungguhnya dapat dibuktikan secara ilmiah melalui methodology kritik hadits, bahkan dengan metode ini dapat menjawab serangan-serangan kaum orientalis yang sengaja ingin

\footnotetext{
${ }^{17}$ Ibid, 71.
} 
menghancurkan Islam dengan menyerang salah satu pondasi dasar ajaran Islam yaitu Hadits.

\section{DAFTAR PUSTAKA}

Al-Qur'an al-Karim.

Abu-Syahbah, Muhammad Muhammad. Fi Rihab al-Sunnah Al-Kutub alShahhah al-Sittah.

Al-Shalih, Subkhi. Membahas IImu-IImu Hadits, (diterjemahkan dari Ulum al-Hadits wa Musthalahuha oleh Tim Pustaka Firdaus), 1995, Cet. II, Pustaka Firdaus, Jakarta.

Azami, Muhammad Musthafa. Memahami Ilmu Hadits; Telaah Methodologi dan Literatur Hadits, (diterjemahan dari Studies in Hadith Methodology and Literature oleh Meth Kieraha), 2003, Lentera, Jakarta.

Fazlurrahman dkk. Wacana Studi Hadits Kontemporer, 2002, Tiara Wacana, Yogyakarta.

Ittr, Nuruddin, Manhaj al-Naqd Fi Ulum al-Hadits, 1998, Dar al-Fikr, Beirut Libanon.

Mandhur, Ibnu.Lisan al-Arabi, Jilid II, Dar al-Fikr, Beirut Libanon. 